\title{
DEMOCRACIA E EDUCAÇÃO: CONSELHOS MUNICIPAIS COMO ESPAÇOS DE APRENDIZAGEM
}

Fernando Henrique Guisso

\begin{abstract}
Resumo
O objetivo do presente artigo é analisar o potencial educativo e integrador existente no interior das práticas democráticas a partir de teóricos da democracia participativa e deliberativa. Partindo dessa perspectiva, pensar como os conselhos de políticas públicas se encaixam dentro deste paradigma e observar as possibilidades educativas existentes nessas novas instâncias. Para tal, recorreremos a entrevistas com diversos conselheiros que fizeram parte do Conselho de Acompanhamento e Controle Social do FUNDEF nos seus dez anos de existência na cidade de Juiz de Fora. Concebendo que essa experiência possui pontos em comum com os demais conselhos, e assim contribuir para a melhor compreensão desses espaços públicos não meramente como aparelhos de gestão, mas como espaços que auxiliam a construção de uma nova cultura política mais participativa.
\end{abstract}

Palavras-chave: Participação; Democracia; Educação Não-Formal; Conselhos; FUNDEF.

\begin{abstract}
The objective of this paper is to consider the potential of educational and integration in the existing democratic practices starting from the theorists of participatory and deliberative democracy. From this perspective thinking about how public policy councils fit into this paradigm and look at the existing educational opportunities in these new instances. To this end, we will draw resort to interviews with several counselors who were part of the Council of Social Monitoring and Control of FUNDEF in its ten years of existence in the city of Juiz de Fora. Conceiving that this experience has in common with other councils, and thus contribute to a better understanding of these public spaces not merely as instruments of management, but as spaces that help build a new political culture more participatory.
\end{abstract}

Keywords: Participation; Democracy; Non-Formal Education; Councils; FUNDEF.

\section{Introdução}

O presente trabalho se propõe a realizar uma análise das inovações democráticas que se inserem no marco dos debates acerca da democracia participativa e deliberativa, mais precisamente tentando observar o caráter 
educativo da participação dentro de instituições híbridas ${ }^{1}$. O objeto deste é o Conselho de Acompanhamento e Controle Social (CACS) do Fundo de Manutenção e Desenvolvimento do Ensino Fundamental e Valorização do Magistério (FUNDEF). Os dados que utilizaremos foram coletados pelo grupo Política e Sociologia da Educação da Universidade Federal de Juiz de Fora, coordenado pela Profa. Dra. Beatriz de Basto Teixeira, no projeto Financiamento da Educação em Cidades Mineiras: dez anos de FUNDEF (1998-2007).

Visamos, através deles, demonstrar o potencial e os limites desses novos espaços de participação e deliberação no tocante aos processos educativos responsáveis pela absorção e transformação da cultura política dos indivíduos participantes.

Os conselhos gestores de políticas públicas e temáticos, no seu formato híbrido, são fruto de inovações democráticas que ocorreram no Brasil a partir do processo de transição que marcou o fim do regime militar, instaurado na década de 1960. A Constituição Federal de 1988 foi responsável pela abertura para novos espaços de participação política onde o povo estaria, assim, mais próximo das decisões políticas. Esses conselhos tomaram forma a partir de leis orgânicas pertinentes a diversas áreas de direitos, como a Lei Orgânica de Saúde (LOS) e a Lei Orgânica de Assistência Social (LOAS). Estavam, assim, instaurados espaços onde estão presentes tanto a sociedade civil quanto o Estado, na forma de seus representantes. Os diferentes conselhos teriam liberdade de regulamentar sua existência a partir regimentos internos, mas seguindo diretrizes maiores, como a necessidade de paridade ou uma forte representação da Sociedade Civil, que garantisse, assim, um real avanço em relação ao formato representativo, consagrado no sistema político partidário. No entanto, os conselhos não ficaram restritos a áreas como Saúde e Assistência Social, mas se proliferaram para as mais diversas áreas de diretos bem como em diferentes temáticas. Dentro deste contexto, no ano de 1996, foi criado o FUNDEF e, dentro dele, os Conselhos de Acompanhamento e Controle Social, espaço que se encaixa, apesar de ser somente fiscalizatório, dentro da realidade dos conselhos de políticas públicas.

O FUNDEF foi a principal política de financiamento da educação que esteve em vigência no período que vai de $1998^{2}$ a 2007 , quando ocorreu a transição para o Fundo de Nacional da Educação Básica (FUNDEB), fundo de natureza mais ampla. Ele foi criado a partir da Emenda Constitucional (EC) $n^{\circ}$ 14 de 12 de setembro de 1996, regulamentado pela Lei $n^{\circ} 9.424$ de 24 de dezembro de 1996 e pelo Decreto n 2.264 de 27 de junho de 1997 e implantado nacionalmente em 10 de janeiro de 1998. O FUNDEF operava dentro de uma mecânica que enviava dinheiro direto aos municípios a partir de um cálculo baseado na quantidade de matrículas e um valor aluno/ano

\footnotetext{
${ }^{1}$ Os espaços de participação como conselhos de políticas públicas e o orçamento participativo são considerados híbridos, pois possuem representantes tanto da sociedade civil quanto do governo, se diferenciando de conselhos populares, comunitários e estatais (AVRITZER e PEREIRA, 2005).

2 Em alguns municípios a implantação do FUNDEF se deu ainda em 1997.
} 
mínimo. Ao operar dessa forma, ele realizou uma redistribuição intraestadual, tomando dinheiro de alguns municípios e redirecionando-o para outros a fim de complementar o valor aluno/ano.

Esse recurso enviado deveria atender a uma repartição que determinava que, no mínimo, $60 \%$ dos recursos deveriam ser investidos na remuneração de professores e na valorização do magistério. Os outros $40 \%$ poderiam ser direcionados para outras áreas definidas pela lei $^{3}$. Para fiscalizar a aplicação correta desses recursos, a fim de minimizar casos de corrupção e de usos irregulares da verba, foi criado o CACS do FUNDEF, que era formado por atores da sociedade civil, representantes de categorias trabalhistas ligadas à educação e do governo.

No presente artigo caminharemos a partir da teoria democrática, demonstrando a contraposição apresentada pelos teóricos da democracia participativa aos teóricos e defensores da visão elitista. Trataremos também das modificações e críticas que a teoria participativa sofreu, gerando uma perspectiva que se foca na importância da deliberação e da comunicação no interior da democracia. Não basta o alargamento dos espaços, mas também sua qualidade. Ao passarmos por esse trajeto de avanços e debates sobre a democracia, já na segunda seção, realizaremos um esforço de relacionar essas discussões à possibilidade dessas arenas serem transformadoras da cultura política operando como espaços de educação não-formal.

$\mathrm{Na}$ terceira seção apresentaremos nossos dados juntamente com uma caracterização dos conselhos. Os dados são, fundamentalmente, entrevistas coletadas junto aos conselheiros de todos os segmentos e das diferentes gestões ao longo dos dez anos de existência do fundo. A partir disso poderemos pensar com mais profundidade se realmente existe uma realidade de aprendizado, como ela se dá e de que formas.

Por último, concluindo o artigo, iremos apresentar nossa interpretação acerca dos dados e lançar hipóteses e posicionamentos sobre o potencial educativo dos conselhos e sua influência para a construção de uma nova cultura política baseada na participação.

\section{Democracia, elitismo e participação}

A democracia é um modelo de governo nascido na Grécia, que operava de forma direta, sem representantes, uma vez que todos aqueles que eram considerados cidadãos possuíam o direito de se manifestar e de ser eleitos para os cargos públicos. O poder estava então concentrado na mão dos cidadãos. Apesar de ser fascinante pensarmos um formato político onde 0 povo possa se apresentar de forma direta, não nos cabe focar na trajetória ou no modelo grego de democracia, mas sim nas manifestações posteriores, que terão como fundamento elementos advindos desse formato.

\footnotetext{
3 O investimento dos $40 \%$ restantes do recurso somente poderia ser aplicado em áreas permitidas pela lei. Não havia completa liberdade do gestor.
} 
Não são necessárias ressalvas ao afirmarmos que a democracia se tornou o principal modelo político na modernidade, ainda que haja muitas diferenças em seus formatos. Um fenômeno de tão grande dimensão atraiu um grande número de teóricos que não se limitaram a analisar modelos, mas agiram de forma propositiva, entendendo a democracia como superior aos modelos anteriores por diferentes motivos. A democracia que nos importará tratar é aquela que se desenvolveu em um mundo que é direcionado por uma lógica liberal e que opera em um sistema capitalista que estratifica a sociedade gerando classes. Seguindo esta lógica, Macpherson (1978) identificou vários modelos de democracia que se enquadraram neste paradigma, sendo eles: Protetiva, Desenvolvimentista, de Equilíbrio ou Elitista e Participativa. Um último modelo que nos interessará tratar será o Deliberativo. Sobre estes modelos, faremos uma rápida apresentação de cada um deles, uma vez que não é nosso objetivo compará-los profundamente, mas, através da discussão, observar os aspectos educativos imputados à democracia em cada um deles ou desconsiderados em outros.

A herança do absolutismo foi o medo de que a vida dos indivíduos pudesse ser dominada e escravizada por um estado autoritário. Neste ambiente se desenvolve uma proposta de democracia que funcionaria como instrumento de proteção aos cidadãos de governantes que se enquadrassem nesse perfil. Fica, assim, fácil compreender a denominação "protetiva", utilizada por Macpherson. À frente desse modelo estavam alguns dos teóricos do utilitarismo, Bentham (apud MACPHERSON, 1978) e James Mill (apud MACPHERSON, 1978), preocupados em garantir que os indivíduos pudessem gozar de suas liberdades, vêem a democracia como a ferramenta que garantirá que o governo não abuse de seus cidadãos e que não se caía novamente em regimes absolutistas.

Por sua vez, é o segundo modelo analisado por Macpherson que terá grande importância em nossa análise. Segundo o autor, John Stuart Mill, filho de James Mill, teve uma visão diferente de seu pai sobre o que realmente significava a democracia. Para este autor era um modelo político que não se limitava a uma ferramenta de administração política, mas tinha um caráter educacional que não se limitaria à esfera política, mas a toda a vida social. Anterior a Stuart Mill, Rousseau (2002), considerado um dos primeiros teóricos da democracia, defendeu essa dimensão da participação política. Trataremos melhor dessa comparação adiante, quando abordaremos o modelo participativo. Além da dimensão educacional da democracia, ele percebia que era na dimensão local onde a participação política deveria se desenvolver. O povo deveria aprender a participar em sua própria cidade ou bairro. No entanto, se faz necessário elucidar que para este autor o poder de decisão não deveria estar na mão do povo, mas este deveria participar no sentido consultivo e fiscalizatório. Não seria então uma real ruptura com o modelo anterior em termos práticos, mas abria possibilidades para se pensar a democracia dentro de um marco diferenciado. A partir de Mill surgiram muitos teóricos do modelo desenvolvimentista, mas todos sempre presos a 
concepções demasiadamente normativas e não reconhecedores da realidade prática. O próprio Macpherson reconhece que muitos elementos presentes na obra de Stuart Mill não ficam claros ou se perdem ao decorrer da trajetória do autor.

O terceiro modelo, o de equilíbrio, ou elitismo democrático, surge com a obra de Joseph Alois Schumpeter, Capitalismo, Socialismo e Democracia (MACPHERSON, 1978; LIMA, 1997). Esse modelo parece ressuscitar o medo destacado por Tocqueville, em Democracia na América, sobre a ditadura da maioria, porém de forma diferenciada. Estas seriam perigosas, tendo em si o germe do autoritarismo ou a incapacidade de participar de um processo complexo como a política, devido à irracionalidade intrínseca a ela. A "essência" identificada pelos teóricos do modelo desenvolvimentista é deixada de lado em virtude de um frio realismo, que constata um fato irremediável: as elites devem ser os atores políticos centrais do jogo democrático. As massas ocupam, assim, um papel importante, mas não participativo, de escolher entre as diversas elites e seus interesses, a melhor para governar. A democracia é então reconhecida como um método de seleção de líderes. Esse modelo tem uma grande relevância ao observar a realidade, mas limitou-se demasiadamente diante das possibilidades da democracia. Ao celebrar o modelo representativo do sistema eleitoral, deixou de lado possibilidades de inovar e ampliar a participação. O modelo de equilíbrio não representa assim uma síntese de pensamentos anteriores, mas, através do empirismo e de pesquisas, demonstrar que as idéias do modelo anterior não eram compatíveis com mundo real.

Contrapondo a visão de Schumpeter, e revisando teóricos como Rousseau e Stuart Mill, Pateman (1992) expõe uma visão que alarga e supera a dita impossibilidade de participação das massas, restaurando assim o caráter educativo e transformador da participação. Schumpeter havia colocado todos os teóricos anteriores como teóricos clássicos da democracia, sem reconhecer as peculiaridades que distinguiam de forma cabal algumas obras. Temos então o denominado Modelo Participativo.

De Rousseau, Pateman recupera o caráter educativo da participação. 0 cidadão aprende sobre questões que irão além da vida política:

Como resultado de sua participação na tomada de decisões, o indivíduo é ensinado a distinguir entre seus próprios impulsos e desejos, aprendendo a ser tanto cidadão público quanto privado (PATEMAN, 1992, p. 38).

A participação tem então uma função integrativa, à medida que o indivíduo aprende a compartilhar das questões pertinentes a todo o público, podendo viver a liberdade como a obediência a lei que alguém prescreve a si mesmo (ROUSSEAU, 2002).

De Stuart Mill, a autora recupera também o caráter educativo, que este relacionava à participação, mas também a importância da mesma se dar 
a partir do "local", da dimensão da vida em que o cidadão comum mais compartilha. A participação como elemento diário da vida dos indivíduos seria capaz de alterar suas disposições mentais e levá-los a um novo patamar.

O último autor que ela se utiliza para complementar sua ideia é G.D.H Cole. Ele havia trazido a participação para o contexto do trabalho. Para ele os trabalhadores e operários deveriam participar da administração e da vida local onde trabalham, não só como coadjuvantes, mas reconhecidos também como "donos".

Assim, podemos concluir sobre o pensamento de Pateman, que a participação é algo que vai além do sistema eleitoral, adentrando a esfera do trabalho e toda a vida dos indivíduos. Participação gera então aprendizado. "Quanto mais o cidadão participa, mais ele se torna capacitado a fazê-lo" (PATEMAN, 1992, p. 39).

Macpherson (1978), no mesmo sentido que a autora, propõe uma concepção também participativa, que seria um modelo liberal de democracia, mas que não reconhece a sociedade dividida em classes com a única possibilidade insuperável e fatal, como tinham feito os elitistas. Pensa, assim, um modelo que superasse a noção de apatia e o perigo representado pelas massas se a estas fosse dado o direito de participar. Macpherson, assim como Rousseau, reconhece a necessidade de haver certa igualdade entre os indivíduos, porém para que isso aconteça se faz necessário que haja participação, o que o lança em um problema cíclico. Como seria, então, a democracia participativa em países subdesenvolvidos? É algo que a teoria participativa, até então, não dá conta. Estes autores, no entanto, abrem espaço para fecundos trabalhos que irão além do paradigma elitista.

E importante ressaltar que os autores não propõem a superação ou o abandono do sistema eleitoral partidário e a eleição de representantes através do voto. Esta foi uma grande vitória e não se deve substituí-lo e sim complementá-la. Para ambos, Pateman (1992) e Macpherson (1978), há a necessidade de promover uma participação que vá além do voto, mas jamais o eliminando e sim reconhecendo que participar a cada dois anos de um processo eleitoral não é o suficiente. A crise da representação e a descrença nos partidos e na eficácia da política são bons exemplos de que somente esse tipo de participação não é o suficiente.

Pereira (2007) ao apresentar o modelo participativo desenvolvido por Pateman e Macpherson, os define como agregativos, ou seja, modelos que, apesar de expandirem o alcance da democracia, dão as preferências como dadas e não abordam os processos de construção delas. Apesar de não acreditar que Pateman (1992) e Macpherson (1978) pensavam em uma concepção agregativa, como julga o autor, é fato que não desenvolveram essa discussão em suas obras. Neste sentido, o modelo que virá a trabalhar essa dimensão será o da Democracia Deliberativa.

Nesse modelo não importará somente que haja novos espaços que conjuguem formatos de democracia direta e representativa, é importante que nesses espaços ocorram deliberações públicas, onde possa haver 
transformação de opiniões e posições. Concebe-se, assim, que a democracia ganha legitimidade e qualidade à medida que os atores têm liberdade e agem discursivamente nos espaços públicos. Essa concepção tem forte ligação com a vertente habermasiana, não se limitando a ela, mas criticando-a e refinando-a. Originalmente essa concepção interpretava que o agir comunicativo se daria na Esfera Pública e essa não deveria ser institucionalizada. Entretanto autores contextualizaram a teoria a realidades como a brasileira, e perceberam que a institucionalização de certos espaços inseridos na Esfera pública poderia ser positiva a conquistas de direitos e ao fortalecimento da dimensão deliberativa.

Quando os teóricos e estudiosos da democracia reconhecem as possibilidades de espaços institucionalizados como arenas de deliberação pública, estes se tornam importantes objetos a serem pesquisados. No Brasil, a partir do fim da década de 80 , com o processo de redemocratização, as duas principais experiências que se enquadram nesta lógica serão os orçamentos participativos e os conselhos gestores de políticas públicas (ADAMS et. al., 2007; AVRITZER, 2007, 2009 e 2010; GOHN, 2007; TATAGIBA, 2002). Esses espaços não são tomados como fenômenos isolados, mas são intimamente ligados ao associativismo e ao crescimento e fortalecimento do terceiro setor, haja vista que é por via desses grupos que os espaços institucionais ganharam força e é deles a principal representação da sociedade civil.

Muitos foram os avanços metodológicos nas pesquisas sobre democracia deliberativa no Brasil, especialmente no que tange a pesquisas quantitativas, mas também na análise institucional dos conselhos a partir de variados documentos (AVRITZER, 2010; FARIA e RIBEIRO, 2010; CUNHA, 2007). Esses avanços têm demonstrado um forte caráter participativo nos conselhos de saúde das capitais e potencial nos conselhos de assistência social e dos direitos da criança e do adolescente, apesar de cidades demonstrarem espaços com baixa intensidade deliberativa. No entanto essas pesquisas têm constatado que o potencial deliberativo e participativo dos conselhos tem relação direta com o contexto político local. Dessa forma vemos que cidades com forte associativismo e forte presença dos movimentos sociais no cenário político terão maior propensão a possuir arenas híbridas com alta intensidade deliberativa. Todavia se faz necessário ampliar os estudos qualitativos que observem de perto essa participação complementando variáveis como presença, pluralidade dos atores e análise da participação a partir de atas.

Cunha (2011) produziu trabalhos que tiveram a análise de atas como principal método de pesquisa, porém a própria pesquisadora reconhece os limites e as dificuldades que o mesmo possui, apesar de não desqualificá-lo:

Em relação às atas, fonte secundária dentro da análise documental, um dos grandes problemas é a incerteza sobre a abrangência de seu conteúdo, que pode muitas vezes não 
documentar acontecimentos, discussões e ideias que surgem no momento das reuniões (CUNHA et. al. 2011, p. 306).

De tal forma percebemos que a utilização de entrevistas, conjugada a análise de atas, nos dará a possibilidade de abordar os conselhos a partir de outras perspectivas, como a que se propõe este trabalho (FLICK, 2009). O esforço é, então, de contribuir na variedade de dados a partir do contato direto com os atores sociais presentes nesse tipo de arena, tentando observar a dimensão educativa, acreditando que as questões trazidas desde Rousseau não se esgotaram, debate aparentemente pouco abordado nos estudos mais recentes. A seguir observaremos a influência dos movimentos sociais na educação política e sua íntima ligação com o nosso principal objeto de pesquisa.

\section{Movimentos Sociais, Educação Política e Conselhos de Políticas Públicas}

Como dito anteriormente, os movimentos sociais têm íntima relação com o fortalecimento de espaços públicos no Brasil e com a formação de um público não-estatal. Eles também tiveram importante participação no processo de redemocratização. Atores como a igreja católica e suas comunidades eclesiais de base, associações comunitárias, sindicatos de trabalhadores e o movimento estudantil demonstram bem a variedade de ações que estavam diretamente ligadas à sociedade civil naquele momento.

Gohn (1999), ao analisar esses movimentos, demonstra as possibilidades de educação política e as possibilidades de transformação da cultura política dos indivíduos participantes. Ela observa importantes dimensões de aprendizado que vão de "consciência adquirida progressivamente através do conhecimento sobre quais são os direitos e os deveres dos indivíduos na sociedade de hoje" (GOHN, 1999, p. 17) a uma dimensão que ela denomina como espacial-temporal. À medida em que os indivíduos integram um movimento social, eles têm a possibilidade de conhecer a historicidade do movimento, bem como as reivindicações que se projetam no tempo. Pensar sobre isso os capacita a entender que as instituições e problemas da sociedade também possuem historicidade. A apropriação de todos esses conhecimentos não pode ser tomada como algo intrínseco à participação, pois depende também das lideranças e dos próprios participantes buscarem isso.

Essa forma de educação é classificada como não-formal (GOHN, 2008). É uma modalidade de educação diferenciada da educação formal e informal. A educação formal é aquela que se desenvolve dentro de instituições educacionais, através de um formato sistematizado. A educação informal seria aquela dada desde o primeiro momento da vida de uma criança por sua família e posteriormente pelos amigos, religião e Estado. É aquela educação que absorvermos de forma inconsciente o tempo todo através de processos 
de socialização e sem uma sistematização clara. Diferentes destas, Gohn define a educação não-formal como:

\begin{abstract}
É um processo sociopolítico, cultural e pedagógico de formação para a cidadania, entendendo o político como a formação do indivíduo para interagir com o outro em sociedade. Ela designa um conjunto de práticas socioculturais de aprendizagem e produção de saberes que envolve organizações, instituições, atividades, meios e formas variadas, assim como uma multiplicidade de programas e projetos sociais (GOHN, 2010, p. 33).
\end{abstract}

Propõe-se uma forma de educação direcionada para a construção da cidadania para além dos marcos do mercado, que vise a emancipação social. É uma dimensão de aprendizagem que nasce no coletivo para o próprio coletivo. Identificamos que esse pensamento tem forte relação com as idéias de Rousseau e de Stuart Mill, visando a formação de um indivíduo que se porte de maneira diferenciada diante do público. Entretanto há que se pensar que essa forma de educação não-formal, não é algo dado ou natural dos movimentos simplesmente por serem formados pela sociedade civil. Não nos cabe aqui sacralizar a sociedade civil em contraposição ao mercado e ao estado, uma vez que compreendemos que os mesmos devem ser tomados de forma relacional.

A relação da educação com a política é fundamental, uma vez que a educação é capaz de transformar valores e culturas. Outra passagem de Gohn expressa isso com profundidade:

A educação (formal, não formal e informal), pelo seu papel
formador é o campo prioritário para o desenvolvimento de
valores. E um dos valores importantes que a emancipação
necessita é o da resistência, visto como capacidade de resistir
e enfrentar adversidades, mas também como capacidade de
recriar, refazer, retraduzir, ressignificar as condições
concretas de vivência cotidiana a partir de outras bases,
buscando saídas e perspectivas novas (GOHN, 2010, p. 58).

Os movimentos sociais são uma alternativa à cultura política da desmobilização que acaba por nos lançar dentro dos dois dilemas da democracia contemporânea: 0 da participação e 0 da representação. (PEREIRA, 2007) Todavia não podemos olhá-los com ingenuidade, exacerbando o caráter real de desenvolvimento ou transformação da cultura política hegemônica, carente de participação, construída no decorrer de séculos de história. Acreditamos, assim, que as arenas híbridas de participação contêm em si a possibilidade de aperfeiçoamento de elementos participativos na cultura política, bem como possibilidades que vão além da estrutura organizativa do terceiro setor. 
Nos conselhos os indivíduos entram em contato com outros atores da sociedade civil. São ambientes plurais, por isso abarcam a possibilidade de troca de experiências e de aprendizado com o outro (TATAGIBA, 2002; GOHN, 2007). Ainda no contexto da pluralidade, os indivíduos são levados também a um exercício de tolerância, diante da diversidade de movimentos e representações ali presentes. Em um Conselho de Assistência Social existem representantes das mais diferentes associações. Uma vez que o elemento discursivo é central, os indivíduos têm também a possibilidade de exercitar sua articulação e argumentação. Ao conjugar representantes de diversos segmentos, o espaço do conselho pode ser utilizado em prol da articulação política da sociedade civil para além do próprio conselho. Somado a isso, há a experiência de vivenciar o funcionamento e a burocracia pertinentes ao estado moderno. E, por último, somando todos os elementos anteriores, a possibilidade de vivenciar e observar a política de uma maneira diferenciada, sendo, então, um espaço de transformação da cultura política ou um potencializador das transformações já iniciadas nos movimentos sociais. No entanto é importante chamar a atenção, mais uma vez, para o fato de que esses elementos não são dados a priori, mas dependem da apropriação que os indivíduos fazem desse espaço, bem como, e talvez principalmente, de como o Estado e o gestor público se posiciona diante deles.

Vários trabalhos que demonstram como o poder público pode esvaziar completamente os conselhos através de diferentes táticas, que vão desde a manipulação de regimentos e leis de criação a fim de garantir a primazia de membros representantes do governo, até a retaliação direta de conselheiros contrários às posições governamentais (DAVIES, 2001 e 2003; MORAIS, 2007; GIL, 2008). Recentemente no município de Belo Horizonte (MG) foi apresentada uma proposta de lei que retiraria o caráter deliberativo dos conselhos. Outra forma é impedir que os conselheiros tivessem informação e cursos de capacitação. Sem acesso à informação e ao aprendizado, não é possível participar efetivamente.

Em outra direção, há estudos demonstrando a eficácia e o sucesso de conselhos, especialmente na área de saúde, em funcionar como espaços de deliberação e de conquistas sociais. Os usuários são o segmento com maior grau de deliberação (AVRITZER, 2010). A grande quantidade de conselheiros no Brasil estima-se, seja maior que o número de vereadores, e a proliferação de conferências temáticas por todo o Brasil são outros importantes sinais de expansão e certa qualificação da participação política no país. No caso específico do FUNDEF, oitocentos e oitenta e oito denúncias de irregularidade foram realizadas nos primeiros anos da existência do conselho. Em Juiz de Fora (MG) observamos a melhora progressiva da fiscalização, bem como o funcionamento do conselho como um espaço de memória pública das diversas gestões da educação (GUISSO et. al., 2011).

Esses são importantes sinais da capacidade desses espaços, mas como os indivíduos têm entendido e percebido essa participação? Ela tem os influenciado também nas ações fora do conselho? Eles entendem melhor os 
assuntos públicos a partir de sua participação nesses espaços? A educação não-formal, aos moldes expostos por Gohn, realmente tem se concretizado? Todas essas são perguntas que nos orientarão na próxima sessão, em que analisaremos as entrevistas realizadas com oito conselheiros do CACS do FUNDEF, representantes de todos os seguimentos, mas em diferentes gestões. Realizamos ainda uma entrevista com a secretária executiva do conselho, que nos ajuda a entender como o governo via e orientava o conselho. Não temos o objetivo nem informações suficientes para esgotar 0 tema, mas, a partir do estudo de caso desse conselho em Juiz de Fora (MG), dar subsídios para futuras análises mais amplas e de caráter comparativo.

\section{O que aprendem os conselheiros?}

Nesta seção analisaremos nossos dados a fim de percebermos os processos de aprendizado e a dimensão educacional contidos neste espaço público. Nossos dados são fruto de oito entrevistas coletadas pelo Grupo Política e Sociologia da Educação ${ }^{4}$, do qual fiz parte e também participei da coleta. Os sujeitos pesquisados foram conselheiros de todos os segmentos de diferentes gestões do conselho. As entrevistas foram realizadas sempre individualmente, sendo conduzidas por um ou dois pesquisadores. Optamos por esta metodologia por entender que ela abordava com a profundidade necessária, porém sem perder a validade, nosso objeto. Posteriormente montamos um quadro com os diferentes relatos e a partir dele buscamos analisar e comparar as informações. A partir desses dados, com o auxílio da bibliografia pertinente, tentaremos abordar o tema proposto e demonstrar suas manifestações empíricas.

Antes de adentrarmos a análise das entrevistas, se faz necessário caracterizar o conselho, seu funcionamento e os atores que o compunham. Ao entender o desenho do conselho, podemos mais claramente imaginar seu funcionamento.

O Conselho de Acompanhamento e Controle Social do FUNDEF possuía as seguintes atribuições segundo a lei $n^{\circ}$ 9.424/96 que regulamentava o seu funcionamento:

Acompanhar e controlar a repartição, transferência e aplicação dos recursos do FUNDEF; Supervisionar o censo escolar anual; Aprovar (até 28 de fevereiro) o programa de aplicação dos recursos a serem recebidos por meio do Programa de Complementação ao Atendimento Educacional Especializado às Pessoas Portadoras de Deficiência (PAED),

\footnotetext{
${ }^{4}$ Coordenado pela Profa. Dra. Beatriz Teixeira de Barros, alocado no Departamento de Ciências Sociais, do Instituto de Ciências Humanas da Universidade Federal de Juiz de Fora. O grupo foi Formado em 2002 e conta com alunos das áreas de Ciências Sociais e Pedagogia. Endereço para mais informações: <http://dgp.cnpq.br/buscaoperacional/detalhegrupo.jsp?grupo=08047081BIS $4 \mathrm{DK}>$.
} 
bem como consolidar e encaminhar as prestações de contas ao FNDE, até 30 de abril do ano subseqüente (atribuição estabelecida pela Lei 10.845, de 05/03/2004); Acompanhar e controlar a transferência e a aplicação dos recursos repassados à conta do Programa de Apoio aos Sistemas de Ensino para Atendimento à Educação de Jovens e Adultos e do Programa Nacional ao Transporte do Escolar - PNATE e, ainda, receber e analisar as prestações de contas referentes a esses Programas (BRASIL, 1996).

Como podemos ver a partir do artigo $4^{\circ}$, a principal atribuição do conselho era a de fiscalização e aprovação de relatórios financeiros relativos às transferências realizadas pelo fundo, mas também acompanhar o PAED e o PNATE. É importante ressaltar que o conselho não possuía, então, atribuições quanto a legislar sobre a lei e mesmo definir onde o recurso seria aplicado, sobre o último, o conselho possuía caráter somente consultivo. O CACS do FUNDEF é por excelência uma instância fiscalizatória.

À medida que entendemos as atribuições deste conselho, nos é importante saber quais segmentos possuíam direito a representação. Segundo a lei, fariam parte do conselho:

a) a Secretaria Municipal de Educação ou órgão equivalente;

b) os professores e os diretores das escolas públicas do ensino fundamental;

c) os pais de alunos;

d) os servidores das escolas públicas do ensino fundamental. E onde houver representantes do Conselho Municipal de Educação (BRASIL, 1996).

A lei ainda possibilita a ampliação da participação através da adição de novos representantes (DAVIES, 2006). Alguns atores vêem a possibilidade da utilização dessa brecha pelo Estado para dominar o conselho, no entanto não ocorreu em Juiz de Fora nenhuma ampliação nesse sentido, permanecendo, nos dez anos, os cinco representantes originais. A única diferença foi a inserção dos diretores de escolas ligadas ao ensino fundamental dentro do segmento dos funcionários públicos ligados à educação.

Em Juiz de Fora, seguindo a lei, as reuniões aconteciam uma vez por mês ordinariamente, existindo, em alguns casos, reuniões extraordinárias. As reuniões sempre ocorreram dentro da Secretaria Municipal de Educação (SME). Não havia remuneração e os conselheiros não possuíam apoio financeiro para o transporte. A convocação era feita por carta e também por telefonemas. As regras estabeleciam que se algum conselheiro faltasse cinco vezes consecutivas ele seria desligado do conselho $0^{5}$. A escolha dos membros era feita de forma diferenciada dependendo do segmento. Os representantes

\footnotetext{
${ }^{5}$ Segundo as atas, ocorreu somente um caso de exclusão de conselheiro. Ele era representante dos pais de alunos.
} 
do governo eram delegados pela secretária municipal de educação; os representantes dos professores eram indicados pelo sindicato dos professores, SINPRO; os representantes dos pais de alunos e os dos funcionários de escolas públicas do ensino fundamental eram indicados a partir de eleições convocadas pela $\mathrm{SME}^{6}$; os representantes do Conselho Municipal de Educação eram escolhidos através de uma votação não formal ou indicação caso não houvesse interessados. O presidente do conselho era escolhido através de votação entre todos representantes, cada um com direito a um voto. A partir da terceira gestão houve a indicação do MEC para que a presidência do conselho não fosse do representante do governo.

Em trabalho anterior, desenvolvido pelo grupo de pesquisa Política e Sociologia da Educação da UFJF, observamos que as pautas tinham como principal tema a análise e discussão dos balancetes financeiros. Outros temas que aparecem nas atas são discussões sobre remuneração dos professores, relatos de treinamentos e relatos sobre visitas a obras desenvolvidas pela prefeitura e financiadas pelo FUNDEF, no entanto ocorrem sempre de forma pontual. As atas foram feitas de uma forma que não descreve os debates sobre os temas, a não ser que os mesmos não existissem. Caracterizamos, assim, nosso objeto.

Os conselheiros advêm de trajetórias de participação diferenciadas, facilmente divisíveis em três perfis: técnico, político e prático. É possível relacionar esses perfis com cada segmento, não os tomando como absolutos, mas como tipos ideais. Os representantes governamentais têm uma trajetória ligada ao conhecimento técnico na área contábil ou de gestão, áreas nas quais desempenhavam funções nas suas respectivas carreiras regulares na SME. São por excelência representações do perfil "técnico". Os profissionais da educação, especialmente os professores, caracterizaram sua participação por argumentos políticos e por lutas relacionadas a suas trajetórias sindicalistas. São os que melhor se enquadram no perfil "político". Os pais se enquadram dentro do perfil "prático", sempre relacionando suas ações a uma atitude prática de fiscalização e relação com seus contextos específicos, suas experiências cotidianas. O representante do CME apresenta um perfil misto entre técnico e político. Há nele preocupação em cumprir a função da fiscalização, mas também realizavam exposições de claro caráter político. Os representantes dos funcionários ligados à educação fundamental apresentam um misto de político e prático. Observamos que esses três perfis demonstram também dimensões em que a educação pode ser desenvolvida dentro destes espaços, especialmente a partir da troca de experiências entre os diversos conselheiros.

O Conselho do FUNDEF é uma instância fundamentalmente contábil. Ao dizermos isso não estamos de forma alguma desconsiderando a central importância política desse espaço, mas ressaltando a principal função

\footnotetext{
6 A SME enviava cartas para todas as escolas de ensino fundamental, solicitando dois representantes que posteriormente seriam eleitos entre seus pares.
} 
institucional do conselho: a fiscalização. O argumento técnico tem grande peso no contexto discursivo do conselho. É ilógico qualquer posicionamento que queira eliminar essa forma de argumento e sua importância dentro desse espaço público. O que nos resta criticar é sua falta de socialização. Tatagiba demonstra que o princípio de paridade que rege a formação dos conselhos deve englobar também os conhecimentos necessários à participação e o acesso equitativo às potencialidades deliberativas destes espaços públicos. Porém, o contato com ele já leva os diferentes segmentos a se colocarem diante de um novo conhecimento necessário à discussão. São forçados assim a aprendê-lo, ainda que de forma simplória. Esse conhecimento não se limita à contabilidade, mas também da burocracia estatal, de dispositivos legais e da relação de poderes existentes dentro do Estado Moderno. Obviamente a falta de treinamento e a aquisição forçada acabam por prejudicar o processo, resultando em dominação governamental ou completa apatia de alguns conselheiros, no entanto nosso objetivo aqui é demonstrar a possibilidade desse aprendizado técnico, entretanto, de vital importância.

A segunda dimensão importante de uma arena participativa envolve seu caráter político. Os participantes são levados à discussão e a argumentação, expondo suas posições e redefinindo-as a partir da racionalização dos diversos argumentos apresentados. Esses processos levam os indivíduos a um exercício de tolerância e aprendizado com o outro:

Eu acho que todos levaram muito a sério. Pelo menos os que eu andei convivendo com eles, em termos de presença, participação, pais, representantes do sindicato que é mais independente ainda, por que eles tem uma posição que é deles e agente também, muitas coisas agente concorda, na questão da lisura da prestação, da transparência, do acesso a informação, tudo isso e eu acho que havia o, sempre houve certa harmonia na responsabilidade, e tudo isso, o que chegou hoje se deve a estas questões que agente foi discutindo, pedindo (sic) (Representante do CME).

Ainda nesse sentido:

Quando não entendem, de repente uma coisa que é óbvia pra você, de repente não é para um pai de aluno, tem total liberdade e até, graças a Deus, ter a liberdade de perguntar, de conferir, de comparar. Eles são atuantes. Sofrem limitações como eu disse, mas limitações que não são culpa deles. Limitações deles não, nossa. Porque eu me incluo também (sic) (Representante dos Professores).

O conselho possui ainda uma dimensão clara de transformação na perspectiva dos conselheiros acerca da política, fruto da experiência da participação: 
Nossa eu acho importantíssimo. Primeiro é tirar a imagem que sempre o governo está roubando, acho isso importantíssimo e eu aprendi muito com isso. Porque sempre a gente fala que o governo rouba, que todo mundo rouba, então é parar com isso e acreditar no poder mesmo do governo, de agir com responsabilidade, de você estar contribuindo. Se realmente acontece isso como a gente ouve falar, pelo menos aquilo que você pode participar e que você pode entender, você viu que é uma coisa clara (sic) (Representante dos Funcionários).

Participar de uma esfera onde são discutidos aspectos da vida pública amplia a visão de pertencimento e de responsabilidade para com a comunidade:

[...] então ele pode largar o serviço de conselheiro, porque ele já é um serviço não remunerado, então por ele não ser remunerado, você pode bater mais de frente. Você não tem perigo de perder, você não é empregado, de ninguém. Você é empregado da comunidade. Então você ta ali defendendo, não é o direito deles. É o meu direito, o seu direito, o direito da comunidade (sic) (Representante dos Pais).

Os dois trechos citados acima corroboram a perspectiva de Pateman (1992) em consonância com Rousseau e Stuart Mill. A participação em um espaço público local, assim como pensava Mill, trouxe a possibilidade de contato de representantes de diversos segmentos da sociedade com uma realidade de gestão pública, até então vivenciada somente através de discursos sempre mediados por outros interlocutores. Em oposição à concepção elitista, onde as massas estão limitadas a ações que levam ao autoritarismo ou que são cheias de irracionalidade, os entrevistados, aspecto claro no discurso do pai, demonstram o desenvolvimento de uma mentalidade voltada ao bem comum. A figura do cidadão que ocupa o papel do soberano, mas que ao mesmo tempo é alvo daquilo que legisla, na figura de cidadão, surge.

O último aspecto é o prático. Essa dimensão leva os indivíduos a um contato com a realidade prática. Uma das atribuições tomadas pelo conselho foi a de fiscalizar as obras desenvolvidas com o dinheiro do fundo. Os conselheiros representantes dos Pais, mais fundamentalmente um dos pais, realizavam essa fiscalização com seus próprios recursos, inclusive seu tempo extra-reunião. Ações como essas trazem uma dinâmica, enriquecendo a discussão com impressões trazidas da vida cotidiana. Há, dessa forma, ganho através de uma dimensão não-escolar de ensino. As experiências diárias e práticas dos indivíduos devem ser vistas como uma importante ferramenta de conhecimento da realidade. Para alguns participantes é o principal fundamento de seu discurso, todavia, não advogamos, de forma alguma, que essa dimensão seja tomada como única e inquestionável. Alguns relatos nos mostram a importância dessa dimensão: 
Olha o que eu pude ver da minha época, dois representantes de pais que foram show de bola, o Sérgio e mais um senhor, eles arregaçavam manga mesmo, eles iam verificar o que estava sendo feito (sic) (Representante dos Funcionários).

Essas são as três principais dimensões que observamos e, assim como nos perfis, não devem ser tomadas como absolutas ou restritas dentro de uma só dimensão. Devemos antes observá-las de forma relacionada e que se interafetam. Todo esse aprendizado ocorre, entretanto não se pode ter uma visão idealizada. As falas dos conselheiros nos mostram grandes dificuldades nesses processos que consequentemente interferem na qualidade das discussões, da fiscalização e limitou a intensidade educativa desse espaço. Contudo, reconhecer esses espaços como espaços de relevância ao desenvolvimento da participação como um valor, e não somente como uma consequência de mudanças institucionais se faz importante à mudança de paradigmas relacionados à democracia. De tal maneira retomamos um pouco daquela visão que Macpherson (1978) denominou de Desenvolvimentista. Retornar aos moldes atenienses de democracia ou gerar um ideal rousseauniano de autogoverno parece inviável às dimensões que o Estado Moderno tomou, entretanto repensar os moldes democráticos renova a perspectiva fatalista advinda do elitismo e de visões conservadoras da política.

O contato com cada uma dessas dimensões não pressupõe um aprendizado imediato e qualitativamente desenvolvido. É necessário tempo e orientação. Apesar dos conselheiros terem aprendido uns com os outros, existem conhecimentos, especialmente de ordem técnica que eram bastante complexos:

Eu acho que seria muito importante que tivesse alguém dentro do conselho que tivesse uma formação de economia, não sei se seria economia, por exemplo assim um contador, alguém que realmente entendesse de finanças pra poder perguntar mais, pra poder avaliar mais e também alguém eu não sei que função seria, que profissão seria - que conhecesse realmente a responsabilidade de cada pessoa que está ali dentro (sic) (Representante dos Funcionários).

Quanto à legislação e o procedimentalismo relacionado ao FUNDEF e a educação, essas dificuldades foram minimizadas pelo auxílio prestado pela secretária executiva do conselho:

Vinte anos e ela já era funcionária do estado, entendida de legislação, ela é assessora técnica também do conselho municipal de educação, e está por dentro de tudo. Assim, o papel dela é fundamental, o tempo todo a par do cumprimento da lei. Bastante confiável, mesmo que a pessoa 
não saiba ela ... 'que você vê de problema aí? tem algum problema legal aqui? Tem isso tem aquilo...' É uma pessoa extremamente competente para[...], ela é um poço de legislação de educação (sic) (Representante do CME).

A importância de um educador social, nos termos de Gohn (2008 e 2010), se mostra com grande clareza na fala da representante do CME. Porém, a assessora da Secretaria Municipal se focava somente no conhecimento técnico. Pensar no papel de um educador social, como defende Gohn, ou de um assessor, deve ir além de mais uma função desempenhada pelo poder público, haja vista que pode se tornar outro instrumento de dominação. A articulação e a fomentação de elementos da educação nãoformal deve respeitar a pluralidade de um espaço como os conselhos temáticos e de políticas públicas, portanto deve, também, ser uma iniciativa advinda de organizações da sociedade civil. Tatagiba (2002) demonstra a existência de uma ONG que desempenha este papel de suporte aos conselheiros e de formação continuada, todavia essa não era a realidade de Juiz de Fora (MG) naquele momento.

Em relação à questão política foi possível perceber que, apesar do fortalecimento de uma visão pública, os representantes, além dos professores e do CME, não passam as informações adiante e continuaram a ter grande dificuldade de articulação com seus segmentos. O caráter deliberativo que tem grande enfoque nos recentes trabalhos se desenvolve dentro dos conselhos, porém o caráter de expansão defendido pelos primeiros teóricos da participação fica amplamente prejudicado, uma vez que as informações não chegam efetivamente nas entidades da sociedade civil. Essa dimensão parece ser a que encontra maiores dificuldade em se desenvolver, haja vista que não é uma dimensão trabalhada pela assessoria e parece não ser percebida com clareza como as demais. O aspecto prático, por sua vez, parece ocorrer de forma mais natural e sem grandes dificuldades, porém esse tipo de conhecimento é muito propenso ao senso comum.

Nesta sessão demonstramos a estrutura do conselho e seu potencial educativo que enquadramos dentro de três categorias: técnico, político e prático. Essas categorias servem também para enquadrar o perfil dos conselheiros baseado em seu comportamento dentro da arena. Lembramos que essas dimensões e perfis não devem ser tomados como absolutos e isolados. Por último observamos algumas dificuldades apresentadas pelos próprios conselheiros e advindos de nossa observação através das atas.

\section{Conclusão}

Pensar o potencial educativo dos conselhos nos ajuda a pensar esses espaços para além de um simples instrumento de gestão. As demandas da sociedade no período marcado pela ditadura militar foram por mais participação, apontando para uma nova cultura política no interior dos 
movimentos sociais. Os conselhos gestores são respostas a essas demandas. Nesse sentido, é importante refletir se eles têm cumprido esse papel e ajudado a potencializar aspectos participativos na cultura política dos participantes e mesmo para além deles. Como apresentamos anteriormente, a existência de um conselho e a presença de atores sociais no seu interior não garantem participação efetiva e nem aquisição das dimensões educativas observadas. O efeito pode ser inverso. Os indivíduos podem ser levados à passividade, ou ao acatamento de decisões governamentais sem qualquer discussão, deliberando ou fiscalizando de forma vazia.

No caso do CACS do FUNDEF de Juiz de Fora (MG), observamos que os representantes dos segmentos perceberam o potencial educativo e efetivamente aprenderam questões pertinentes as três dimensões educativas, porém, especialmente no caso da política, de forma difusa. Observando as entrevistas, percebemos que somente o professor ressalta o potencial de articulação política e de alianças entre os segmentos que o conselho apresenta. A falta de debate de alguns representantes junto aos seus segmentos também demonstra os limites desse aprendizado.

Os diferentes perfis podem ser vantagens, à medida em que os próprios conselheiros aprendem uns com os outros. Ao reunir grande pluralidade de atores, se reunem os diferentes perfis, o que possibilita troca de conhecimentos. Todavia não é algo simples. Eles podem representar ferramentas de dominação, haja vista que o discurso técnico tem grande peso na modernidade. Mais uma vez o governo tem em suas mãos um elemento de desequilíbrio, no sentido negativo.

O que auxiliou os indivíduos foi a presença da secretária executiva, todavia seu suporte focalizou no aspecto técnico. Aqui reconhecemos como seria útil a existência de um educador social ou de algum indivíduo capaz de se aproveitar de todas as dimensões educativas e articulá-las auxiliando os conselheiros a se apropriarem, reconhecendo esses conhecimentos como importantes ferramentas na qualificação da representação política no interior dos espaços públicos. Outros conselhos possuem assessorias técnicas e corpos administrativos, todavia não era essa a realidade do CACS do FUNDEF e também seria necessário pesquisá-las para saber se cumprem esse papel.

A grande variedade de conselhos e de contextos políticos presentes no Brasil nos impossibilita de afirmar cabalmente que o caso analisado é representativo para todas as demais experiências, no entanto acreditamos ser um importante subsídio para observar a intensidade educativa e como ela pode se desenvolver. Não objetivamos esgotar a discussão, mas desenvolvêla, já que são poucos os estudos que caminham neste sentido. Um próximo passo importante, que pretendemos em outras pesquisas, é desenvolver uma análise da trajetória de indivíduos participante e não participantes. Dessa forma poderemos isolar com mais clareza o que eles trazem antes de entrar no conselho, o que aprendem durante a participação e como isso afeta seu posicionamento político depois da participação. Assim poderemos sistematizar variáveis com maior precisão. 
Os teóricos da participação nos deram importantes subsídios para orientar nossa investigação. Pateman, ao se utilizar de G.D.H Cole, nos mostra a possibilidade de vermos diversos espaços da sociedade como espaços de participação e consequentemente de aprendizado. Rousseau, ainda que normativamente, nos mostra características da participação o que também nos serviu como um importante marco. Realizamos, então, uma sistematização de aspectos educativos apontados por outros autores, como Rousseau, Pateman e Gohn e observamos sua manifestação em um estudo de caso.

O avanço na teoria democrática, em especial no sentido do reconhecimento da importância do processo de deliberação, traz novos aspectos da democracia que nos são úteis. Acreditamos que o processo de discussão tem forte dimensão educativa que toca todos os pontos que apresentamos aqui e ainda outros.

No presente trabalho realizamos o esforço de demonstrar o potencial educativo presente dentro das arenas institucionalizadas e híbridas conhecidas como conselhos de políticas públicas. Recorremos, então, aos teóricos da participação e da democracia participativa e deliberativa para trazermos à tona a dimensão educativa presente na participação. Junto a isso realizamos uma rápida discussão sobre a educação não formal e movimentos sociais. Por último caracterizamos nosso objeto, o conselho fiscalizador do FUNDEF, e apresentamos os dados junto a nossa observação de perfis e dimensões educativas existentes na participação no interior do conselho. Continuar observando essas arenas é de fundamental importância para seu aperfeiçoamento, ou mesmo para sua substituição por instituições mais capazes de fortalecer a dimensão da participação, que se configura como um novo elemento de legitimidade no Estado Moderno.

Fernando Henrique Guisso é Mestrando em Ciências Sociais no Programa de Pós-Graduação em Ciências Sociais da Universidade Federal de Juiz de Fora. E-mail: fhgcso@yahoo.com.br

\section{Referências}

ADAMS, Telmo et. al. Controle Social de políticas públicas: caminhos, descobertas e desafios. São Paulo: Paulus, 2007.

AVRITZER, Leonardo. Sociedade civil, instituições participativas e representação: da autorização à legitimidade da ação. Dados, Rio de Janeiro, v. 50, n. 3, p. 443-464, 2007. Disponível em: <http://www.scielo.br/scielo.ph p>. Acesso em: 27 nov. 2010.

(Org.). Experiências nacionais de participação social. São Paulo: Cortez, 2009. 
. A dinâmica da participação local no Brasil. São Paulo: Cortez, 2010.

AVRITZER, Leonardo; PEREIRA, Maria de Lourdes Dolabela. Democracia, Participação e Instituições Híbridas. Teoria e Sociedade, Belo Horizonte, número especial (Instituições Híbridas e Participação no Brasil e na França), p. 212-241, mar. 2005.

BRASIL. Lei $n^{\circ}$ 9.424, de 24 de dezembro de 1996. Dispõe sobre o Fundo de Manutenção e Desenvolvimento do Ensino Fundamental e de Valorização do Magistério, na forma prevista no artigo 30, $\$ 70$, do Ato das Disposições Constitucionais Transitórias e dá outras providências. Brasília. 1996. Disponível em: <http://www.planalto.gov.br/ccivil_03/Leis/L9424.htm>. Acesso em: 14 ago. 2009.

CUNHA, Eleonora Schettini. O potencial de conselhos de políticas e Orçamentos Participativos para 0 aprofundamento democrático. In: DAGNINO, Evelina; TATAGIBA, Luciana (Orgs.). Democracia, sociedade civil e participação. Chapecó: Argos, 2007. p. 25-44.

CUNHA, Eleonora Schettini et. al. Uma estratégia multidimensional de avaliação dos conselhos de políticas: dinâmica deliberativa, desenho institucional e fatores exógenos. In: PIRES, Roberto Rocha (Org.). Efetividade das instituições participativas no Brasil: estratégias de avaliação. Brasília: Ipea, 2011. p. 297-322.

DAVIES, Nicolas. O FUNDEF e as verbas da Educação. São Paulo: Xamã, 2001.

. Conselhos do Fundef: a participação impotente. Avaliação e Políticas Públicas em Educação, Rio de Janeiro, v. 11, n. 41, p. 505-517, abr.-jun. 2003. Disponível em: <www.scielo.br/pdf/ensaio/v14n50/30406.pdf>. Acesso em: 14 out. 2009.

. FUNDEB: a redenção da educação básica? Educação \& Sociedade, Campinas, v. 27, n. 96, p. 753-774, out. 2006. Disponível em <http://www.scielo.br/scielo.php?script=sci_arttext\&pid=S010173302006000300007\&lng=pt\&nrm=iso >. Acesso em: 16 out. 2009.

FARIA, Claudia; RIBEIRO, Uriella. Entre o legal e o real: o que dizem as variáveis institucionais sobre os conselhos municipais de políticas públicas? In: AVRITZER, Leonardo (Org.). Dinâmica da participação local no Brasil. São Paulo: Cortez, 2010. p. 57-92. 
FLICK, Uwe. Introdução à pesquisa qualitativa. 3. ed. Porto Alegre: Artmed, 2009.

GIL, Juca. Conselho do FUNDEF: uma história de atribuições esvaziadas. In: Reunião Anual da ANPEd, 31., Caxambu, 2008. Disponível em: <www.anped.org.br/reunioes/31ra/1trabalho/GT05-4540--Int.pdf >. Acesso em: 09 set. 2009.

GOHN, Maria da Glória. Movimentos Sociais e Educação. São Paulo: Cortez, 1999.

2007.

. Conselhos Gestores e Participação Sociopolítica. São Paulo: Cortez, 2008.

. Educação Não-Formal e Cultura Política. 4. ed. São Paulo: Cortez,

- Educação Não Formal e o Educador Social: atuação no desenvolvimento de projetos sociais. São Paulo: Cortez, 2010.

GUISSO, Fernando et. al. Os dez anos de FUNDEF em Juiz de Fora-MG. Revista Csonline, Juiz de Fora, v. 1, n. 12, p. 96-124, abr.-jul. 2011. Disponível em: <http://www.editoraufjf.com.br/revista/index.php/csonline>. Acesso: 25 jul. 2011.

MACPHERSON, Crawford Brough. A Democracia Liberal: origens e evolução. Rio de Janeiro: Jorge Zahar, 1978.

MORAIS, Peauleany Simões de. Representação e Poder de Decisão: desafios do conselho de controle e acompanhamento social do Fundef. In: CASTRO, Alda Maria; FRANÇA, Magna; NETO, Antônio Cabral; QUEIROZ, Maria Aparecida de (Orgs.). Pontos e Contrapontos da Política Educacional: uma leitura contextualizada de iniciativas governamentais. Brasília: Líber Livro, 2007.

PATEMAN, Carole. Participação e Teoria Democrática. Rio de Janeiro: Paz e Terra, 1992.

PEREIRA, Marcus Abílio. Modelos democráticos deliberativos e participativos similitudes, diferenças e desafios. In: DAGNINO, Evelina; TATAGIBA, Luciana (Orgs.). Democracia, sociedade civil e participação. Chapecó: Argos, 2007. p. 421-454.

LIMA, Olavo. Instituições Política Democráticas: o segredo da legitimidade. Rio de Janeiro: Jorge Zahar, 1997. 
ROUSSEAU, Jean-Jacques. Do Contrato Social. São Paulo: Martin Claret, 2002.

TATAGIBA, Luciana. Os Conselhos Gestores e a Democratização das Políticas Públicas no Brasil. In: DAGNINO, Evelina (Org.). Sociedade Civil e Espaços Públicos no Brasil. São Paulo: Paz e Terra, 2002. p. 47-103.

TEIXEIRA, Beatriz; OLIVEIRA, Rosimar. Financiamento da Educação em cidades mineiras: dez anos de FUNDEF (1998-2007). Juiz de Fora: DCSO/UFJF, 2010.

TOCQUEVILLE, Alexis de. A Democracia na América. São Paulo: Martins Fontes, 2005.

Texto recebido em 01/05/2012.

Aprovado em 18/07/2012. 